\title{
Nurses' Perceived Quality of Educational Life during the Covid-19 Induced Rapid Transition to Online Learning in Post-Graduate Courses: A Qualitative Study
}

\author{
Leopoldo Sarli' ${ }^{1}$ Giovanna Artioli1,2*, Enrico De Luca1, Chiara Moretti ${ }^{1}$,

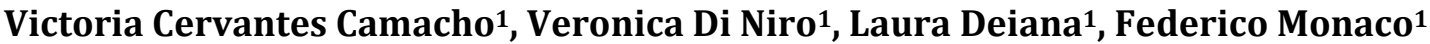 \\ ${ }^{1}$ Department of Medicine and Surgery, University of Parma, Parma, Italy \\ ${ }^{2}$ Azienda USL-IRCCS di Reggio Emilia, Reggio Emilia, Italy \\ Email: ^giovanna.artioli@ausl.re.it
}

How to cite this paper: Sarl, L., Artioli, G., De Luca, E., Moretti, C., Camacho, V. C., Di Niro, V., Deiana, L., \& Monaco, F. (2021). Nurses' Perceived Quality of Educational Life during the Covid-19 Induced Rapid Transition to Online Learning in PostGraduate Courses: A Qualitative Study. Creative Education, 12, 1247-1261. https://doi.org/10.4236/ce.2021.126094

Received: May 4, 2021

Accepted: June 8, 2021

Published: June 11, 2021

Copyright $\odot 2021$ by author(s) and Scientific Research Publishing Inc. This work is licensed under the Creative Commons Attribution International License (CC BY 4.0).

http://creativecommons.org/licenses/by/4.0/ (c) (i) Open Access

\begin{abstract}
This study aimed to investigate healthcare post-graduate students' perceptions of the quality of educational life and learning experience during the forced online transition due to the Covid-19 pandemic. The study design was inspired by a qualitative inductive approach. Participants $(\mathrm{N}=24)$ were nurses who attended healthcare postgraduate courses. In-depth video-recorded interviews were carried out. Thematic analysis was chosen to infer data from the transcripts. Four critical themes emerged from data analysis: 1) the "emotional" change in the quality of life; 2) learning environment and quality of educational life; 3 ) the socio-relational dimension; 4) strategies to improve the educational life. Although initial struggles related to the unfulfilled different learning styles and socio-relational needs, students showed mostly a proactive attitude. They discovered, with the help of online learning, that a learning program could be adapted to their lifestyle. Lastly, study participants highlighted the crucial importance of online tutors to improve their engagement and the quality of educational life.
\end{abstract}

\section{Keywords}

Covid-19 Pandemic, Nurse Education, Online Training, Qualitative Research, Quality of Educational Life

\section{Background}

The beginning of 2020 with the rapid progression of Covid-19 infection wit- 
nessed necessary measures to contain the contagion such as social distancing, isolation, the suspension of many productive activities, closure of schools and universities (Dewart et al., 2020; Ibrahim et al., 2021; Basilaia et al., 2020). In Italy, the school system was mostly based on face-to-face teaching and the health emergency forced a fast shift to online teaching to allow the continuation of training and courses (Cleland et al., 2020). Thus, the forced transition raised researchers and academics concerns on the effectiveness of the online education and training style, mostly perceived from a content and learning outcome perspective (Ramos-Morcillo et al., 2020). Learning process can be influenced by elements concerning qualitative aspects like the students' self-perception, sense of belonging, attitudes towards a profession, motivations, communication skills and academic achievements (Elitok Kesici \& Çavus, 2019).

Our study considered the phenomenon of the quality of educational life from adult learners' perspective who are facing the transition to a forced online learning. The academic quality of life generally represents students' feelings of satisfaction towards their university experiences (Pedro et al., 2016) and factors influencing student's engagement (Martin \& Bolliger, 2018). Three general dimensions compose the concept of quality of educational life: the level of academic satisfaction (e.g., education methods, classroom environment, workload, and academic reputation), satisfaction with the academia facilities and the satisfaction with social aspects (Sirgy, Grezeskowiak, \& Rahtz, 2007; Sirgy et al., 2010; Karimi \& Brazier, 2016). However, the quality of educational life seems to be a less investigated aspect of pedagogy and adult learning theories (Erez et al., 2020).

Several studies documented the effectiveness of e-learning in health professions training (Regmi \& Jones, 2020), albeit the forced transition still raised the issue on the effectiveness of the online learning programs. A consistent body of research showed that there are no big learning outcomes differences between offline and online modality; nevertheless online learning has some advantages (Pei \& Wu, 2019). Some studies have highlighted the advantages of online learning university programs in terms of flexibility, the effectiveness of in-depth study, greater student autonomy, lower costs and time savers (Zhou et al., 2020). However, other studies have identified e-learning obstacles, such as learner isolation and lower participation (Cappi et al., 2019; Regmi \& Jones, 2020). Nurse researchers and academics criticize online learning for its potential lack of the social dimension, which represents a big part of the nursing training programs indeed (Waddington \& Porter, 2021). Authors' opinions diverge on the implementation of postgraduate online education too (Simpson et al., 2020; Martinengo et al., 2020; Jowsey et al., 2020).

The debate on the quality of educational life should also consider stress caused by the general emergency condition, especially for health professionals who are studying and actively involved in direct care activities. Contemporary studies documented healthcare professionals' state of depression (An et al., 2020), anxiety and, more general changes in their personal quality of life due to emergen- 
cy (Korkmaz et al., 2020; Busch et al., 2021) that may had a strong impact on their ability and willingness to learn. In fact, during first wave pandemic in Italy, health professionals faced a double challenge: on the one hand, they were dealing professionally (and personally) with an emerging global health crisis; on the other hand, those enrolled in a university training course dealt with a necessary transition from traditional teaching to online teaching (Langegård et al., 2021; Goni-Fuste et al., 2021).

Although a relevant number of studies on students' general perceptions of their experience of the forced transition to online learning (Langegard et al., 2021; Ibrahim et al., 2021; Goni-Fuste et al., 2021; Bączek et al., 2021), research directed to explore specifically the quality of the educational life and focused on nurses who attend post-graduate professional courses is still lacking.

Our research aimed to explore nurses' perceptions of the quality of educational life during the transition period from face-to-face teaching to online learning due to the first Covid-19 emergency in Italy. Specifically, the study focused on the experience and opinions of nurses who were attending postgraduate health courses and professionally involved during the emergency too.

\section{Method}

A qualitative study was adopted using semi-structured interviews. The methodological approach chosen to infer data from the textual material was the thematic analysis (Braun \& Clarke, 2006; 2014). Thematic analysis, with its adaptable framework, represents a flexible and useful approach to render a detailed and rich account of the complex phenomenon analyzed. "Thematic analysis can be an essentialist or realist method, which reports experiences, meanings and the reality of participants, or it can be a constructionist method, which examines the ways in which events, realities, meanings, experiences and so on are the effects of a range of discourses operating within society" (Braun \& Clarke, 2006: p. 9). In-depth interviews were privileged tools to explore participants' lived experience and their meanings of the quality of their educational life during forced transition to online learning.

\subsection{Participants and Setting}

Our research involved nurses attending post-graduate courses at the Department of Medicine and Surgery of an Italian Northern University. Healthcare postgraduate courses consist of one or two years of academic training directed to professionals who want to achieve further knowledge and qualification on several topics, such as case-care management, infection control, critical care nursing, teaching and learning strategies, palliative care and risk management. In February 2020, the students enrolled in these post-graduate courses with a traditional teaching setting, experienced a sudden and forced transition to online learning. A purposive sample of students participated in our research. Participants eligible criteria were: 1) nursing in clinical settings; 2) minimum 1 year of work expe- 
rience. Students were invited to participate in the study via official e-mail and e-platform communications with an explanation of the research topic, the interview setting and modality. Each participant would receive a bonus in placement hours in appreciation of his or her time spent for the interview.

\subsection{Data Collection}

The interviews were conducted in May-June 2020, using semi-structured questions to collect participants' experiences (see Table 1).

Interviews were video recorded and conducted by four researchers (CM, VDN, EDL, and VCC) with the use of video conference platforms (Skype, Zoom or Hangout). All researchers were professionals from psychology, nursing and anthropology fields with experience in qualitative research methods and leading interviews.

\subsection{Data Analysis}

Interviews were transcribed verbatim by researchers. Researchers agreed to adopt an inductive attitude within the overall analysis process (Graneheim, Lindgren, \& Lundman, 2017); therefore, the themes identified were strongly linked to the data themselves (Patton, 1990).

We followed the six phases of thematic analysis as described by Braun \& Clarke (2006; 2012): 1) familiarize yourself with your data (all researchers were involved); 2) generating initial codes (four researchers performed the initial analysis and shared reciprocal findings, two researchers experts supervised the process); 3) searching for themes (four researchers with experts supervision); 4) reviewing themes (all research team involved); 5) defining and naming themes (all research team involved); 6) producing the report (three researcher wrote the report and all researchers reviewed it).

Table 1. Interview questions.

1 Would you like to tell us about previous university experiences you had before this course?

From your experience, what are the most important aspects and what should not be missing in a traditional university course?

Would you like to tell us, how has your university experience been during the Covid

3 outbreak and therefore the sudden transition to an e-learning mode? Can you give us an example? In your opinion, were there any factors supporting this transition to e-learning regarding the course you are attending? Could you give us an example? In your opinion, were there any obstacles with the e-learning transition related to the course you are attending? Could you give us an example?

6 After this Covid-induced e-learning experience, we would like to know what are your expectations regarding the continuation of your course?

7

Hypothesizing scenarios of an eventual impossible return to traditional teaching settings, would you like to give us your suggestions to improve the learning experience? 
The first analysis step of familiarization implied accurate and repeated reading of verbatim transcripts. Specifically, the four researchers read first each transcript independently and afterwards they paired for a further reading, sharing their preliminary impressions. They defined meaning units within the textual material, such as common words or statements that participants used frequently to describe relevant issues. Researchers carefully observed the meaning units, which strongly emerged, whereas they eliminated redundancies and observed recurrences through content and context. The four researchers compared the data obtained and sought agreement. Two external researchers (GA and LS) analyzed and supervised any disagreements. Secondarily, researchers condensed the most significant agreed units into initial sub-themes. Subsequently, researchers identified main themes containing selected sub-themes, through a process of abstraction and constant comparison (Braun \& Clarke, 2006).

\subsection{Rigor}

Researchers were $\mathrm{PhD}$ prepared professionals with a wide experience in qualitative research methodology. The research team guaranteed rigor adopting an accurate data collection, regular inter-analysis meetings to share findings, exclude non-fitting themes and reach a consensus (Braun \& Clarke, 2006). Research validity was supported by actualizing an ordered and traceable series of cognitive acts, like the process leading to theme creation. We used criteria for conducting good qualitative research with analyst triangulation; thus, multiple researchers reviewed findings (Patton, 1999). Besides, transferability was ensured by describing the setting, participants' characteristics and selection, the data collection process and analysis (Nowell et al., 2017). Finally, the COREQ checklist for qualitative research was also compiled (Tong et al., 2007).

\subsection{Ethical Considerations}

Research permission was granted by the University Data Protection Service, which adopted their official consent form for the nature of the research. Participants were verbally informed of their rights before the beginning of the interviews; therefore, they provided written consent to participate. Participants agreed to be video-recorded and were reminded of their option to stop participating at any time. All data was kept in a university security e-folder according to research government regulations.

\section{Results}

Nurses $(n=24)$ from five different postgraduate health care courses were interviewed. The main participants' characteristics are highlighted in Table 2.

The length of interviews varied from 25 to 58 minutes, depending on participants and interviewers' willingness to explore and deepen the topic.

The analysis of the interviews showed, in a transversal way, homogeneous changes in the perception of students concerning the quality of educational life, 
Table 2. Participants demographic characteristics $(n=24)$.

\begin{tabular}{ccc}
\hline Age (mean and range) & \multicolumn{2}{c}{$43(24-58)$} \\
Sex (n) & Women & 20 \\
\hline Work experience (Years) (mean and range) & Men & 4 \\
\hline Previous on-line courses experience (n) & \multicolumn{2}{c}{$19(1-39)$} \\
\hline Previous post-graduation traditional courses (n) & Yes & 7 \\
& No & 17 \\
& Yes & 11 \\
\hline
\end{tabular}

experienced during the digital transition. The changes were perceived on a cognitive, emotional, relational and social level.

Four main themes emerged from analysis: 1) the "emotional" change in the quality of life; 2) learning environment and quality of educational life 3) the socio-relational dimension; 4) Strategies to improve quality of the educational life.

\subsection{The "Emotional" Change in the Quality of Life}

The first theme described the consequences of emergency on participants' quality of life and the transition from a negative emotional dimension into another that is open to change. Three sub-themes identified: 1) the consequences of Covid-19 on professional and personal life 2) the initial disappointment, 3) positive emotions and openness to change.

1) The consequences of Covid-19 on professional and personal life.

Participants highlighted their emotions related to Covid-19 experience; they were also directly involved as nurses in the global emergency. In fact, they expressed mental and physical fatigue (cod. 27.8) lack of concentration (cod. 27.8), or a more general sense of uncertainty about the future (cod. 9.12) and concern (cod. 9.28) for the impact of the health emergency on professional and family life. In some cases, a certain degree of skepticism emerged (cod. 11.4), leaving professionals with some unanswered questions and concerned by the fact that nothing will be the same again (cod. 11.2). A participant affirmed:

"The impossibility to participate because there are those who were in the front line wards, the ones who are on the front line were objectively unable to participate [to the course] or because ... or because they got sick ...." (code 3.10)

2) The initial disappointment

In addition to the fear of the uncertainty of the future, the participants initially experienced "a bit of a cold shower because my expectations when I chose [the course] were different compared to what we have now" (cod. 27.25) with the course shifting quickly into online learning. Some of the students declared an initial disappointment (cod. 8.11), surprise (cod. 9.11) and a sense of inadequacy (cod. 9.11), related to the fear of the use of technology. The greatest perplexity seemed to be of "not being able", at the end of the course, to reach the same 
(learning) objectives (cod. 4) or to attend a learning pathway considered less "rich" in content than a traditional one (cod. 4.18, 27.15).

"P $m$ afraid, however, that people tend to be less careful in front of the computer, at least I see that sometimes I get distracted more easily, precisely because you have this fixed image" (code 7.5)

3) Positive emotions and openness to change

The participants, in general, perceived the shift from an initial negative emotional dimension into experiencing more emotions that are positive and openness to change:

"Yes, in my opinion, it was a great thing (learning how to use online technology) because they could have canceled everything or blow up the academic year. In reality ... it has been an exciting year because it has also allowed me to overcome, to have an outlet ... from ... from Covid ..." (cod. 22.8).

"The e-learning platform was fantastic because in part you could be in presence; in part, it was recorded either by the teacher or by colleagues ..." (code 22)

Participants recognized that the use of e learning has allowed them to continue their training and to overcome the negativity that Covid had generated in the quality of their life.

\subsection{Learning Environment and Quality of Educational Life}

The issue related to learning environment highlighted the participants shift from an initial need to share physical spaces to the discovery of new places for socialization. Two sub-themes merged into this theme: 1) the sharing of learning "spaces"; 2) the discovery of new learning environments.

1) The sharing of learning "spaces".

The students stated the importance of sharing a physical space to implement a particular educational environment that favors concentration, such as the cohabitation of the classroom (code 1.2) and the being in the same physical places (cod. 23.8). Nevertheless, traditional social and educational settings were no longer possible in this transition phase. The online learning environment, described by students as a "non-place", frightened and generated personal crisis or distrust, because, for example "you find yourself alone facing your computer, in your home" (cod. 7.3). Thus, the new online learning setting generated feelings of being "just a little, I don't know how to say, it's just you and yourself because you lose a bit of contact" (cod. 4.10) and to experience a feeling of loneliness.

2) The discovery of new learning environments.

Some students, reflecting on the new learning setting, appreciated the new environment and ways of learning.

"It's not the course I expected to attend, but I prefer, rather than having it closed, not having done it, I prefer (nods) definitely, given the current situation .... (raises eyebrows), to do this ..." (cod. 7.5).

"... in truth, as a group of students, we are more in touch now than before. I think that if we were 'in presence' we would just say goodbye after the teaching 
and go away ... now we are more technological and we meet also after the lessons and we create groups" (cod. 18.8).

\subsection{The Dimension of Interpersonal Relationship}

The socio-relational dimension emerged strongly within the transcripts. This theme identified the participants shift from perceptions that the only way of relating each other is represented by the interaction and presence in the classroom, to discovering new forms of socialization. Two sub-themes merged into this theme: 1) Interaction with others; 2) The discovery of new ways of socialization.

1) Interaction with others

This sub-theme was characterized by concepts such as interaction (cod. 23) and involvement (cod. 1.1, 18.1). Throughout the codes that described the relationship concept, some participants highlighted fundamental aspects of this concept, inherently linked with the nursing professional nature. These aspects were human contact (cod. 23.14), in the specific form of empathy (cod. 9.17) and the complicity between students that is generated within the traditional setting. Participants affirmed that the relationship between students and teachers in physical presence creates "new inspirations" (cod. 23, 17.2) generated by comparison (cod. 18.3) and the sharing of personal experiences which stimulate learning (cod. 11.9). A participant affirmed:

"[I] hope that we will soon return to the physical presence in classrooms. I can't think about the fact that more and more nurses are trained with e-learning, because ours is a work made of relationship and losing the relationship with the colleague then does not help in the other relationships we create too ..." (code 17.2).

2) The discovery of new ways to socialize

After initial disorientation, many participants affirmed that they have begun to appreciate online learning (cod. 11.4) as a means that also allowed them to discover a new type of socialization. They claimed to have created a community over time, participating virtually, more than in the traditional situation (cod. 12), meeting on different platforms, getting to know each other and sharing their experiences. A participant stated, “when we connect ... it is as if we were [physically] present all together" (code 19.02).

\subsection{Strategies to Improve Quality of the Educational Life}

This theme showed the participants' transition from an idea of problematic learning to an overall experience of proactive educational life. Three sub-themes highlighted contrasting elements within participants' perceptions: 1) the technology as a limit and resource; 2) Student's positive attitudes towards learning experience; 3 ) Being coached in the educational path.

1) Technology as a limit and resource

Some participants, more accustomed to the rituals related to technical-practical courses, expressed concerns and difficulties with the use of ICT for 
educational purposes. Although participants recognized the flexibility of online learning in terms of more time and better management of educational content, they would opt for a return to a traditional or blended learning method. Conversely, nurses involved in complex professional and clinical contexts, tackling health emergencies found useful the improved study-time management (codes $18.21,17.5)$. Indeed, a second group of participants appreciated the great benefits of this new teaching methodology and openly wished it would be maintained in the future. The participants considered online learning "an innovative way" (code 25) because "it allows you to experiment and share teaching materials with Google Drive" (code 18), to be constantly in contact with each other and to interact directly with the teacher through electronic platforms (code 18).

Here are two conflicting statements, highlighting these different opinions:

For me, it was quite difficult (nods head) because I do not really have a great relationship with technology .... I accepted it willingly because at least we have not lost other days of study .... (code 3.15)

The platforms that they have suggested were meet, skype, zoom, and they worked well. So if the connection is good, you have a good one ... you do not get bored. The fact that they also recorded [the lessons] gave you a chance to say: if I really cannot make it, I will watch it for half an hour, I will watch it 3 - 4 hours in the evening ... (code 22)

2) Student's positive attitudes towards learning experience

Some participants identified personal will (25.1) fundamental to help to transform this new teaching methodology into a thorough learning experience. They highlighted how online work increases the degree of autonomy of students (code 11.5, 9.14), "stimulating" them to develop new skills (code 11.5) and stimulating self-training attitudes. Some participants considered online learning not solely a valid methodology but a better alternative to the perceived passive traditional teaching setting too (code 5.13).

"Let's say that in the first place the experience was of concern for health but after the idea was: ok, now let's try to roll up our sleeves and see how to deal with this new method, telematics one and that's it!" (code 9.28)

3) Being coached in the educational path

In the new problematic situation, the participants suggested strategies for the improvement of online training, among these, there was "supporting personalized learning" (cod. 17.14, 18.19). Personalized education goes beyond collective needs, apart from moments in small groups. The teacher (or online tutor) increased the opportunities to share opinions between students (code 4.17), minimizing technological obstacles (code 20.10, 20.11, 20.17) and favoring the development of effective interactions. Participants particularly appreciated the presence of the tutor; therefore, they acknowledged that specific tutors supported them in their teaching work: "(...) the tutors really opened up and told us you can do this or it will be like this".

"I find the presence of a tutor very useful for masters who acts as a mediator 
between the teaching platform, the teachers and the teaching subjects and the students in such a way as to be able to have a reference, a form of accompaniment in the path of studies" (code 10.1)

The tutor' support allowed the participants to face the difficulties arising from working in clinical settings, in the Covid era.

“(...) first because we all work, or we are involved in clinical activities and, in addition of being stressed and tired from our activity (...) it is not possible to ask for study leave so easily..." (code 22.6).

\section{Discussion}

This study aimed to explore post-graduate students' perceptions of the quality of their educational life during the forced transition to online courses.

Even during the normal time, the topic of the quality of educational life seemed to be less investigated (Elitok Kesici \& Cavus, 2019). Conversely, other educational fields of studies such as online learning have been the subject of research for decades (Aitken, 2020). In fact, recent studies regarding covid-19 experiences of nursing students highlighted mostly the effect of the transition from face-to-face to e-learning education (Pierce et al., 2020) rather than the complexity of the overall quality of educational life.

Emerging themes from our analysis showed the changing features of the educational life of the students throughout their perceptions of the digital challenges, new logistics, affective and socio-relational landscapes. Nurses, attending post-graduation courses, experienced and reflected on their personal shift from initial negative emotions for the not-chosen educational situation towards an opening for the new perspective adopting a collaborative attitude and the activation of inner resources.

Our study participants were nurses mostly working in hospitals or community healthcare settings; thus, the influence of the participants' professional setting was an important factor to consider, too. During the lockdown period, fear was one of the predominant feelings and students highlighted how the forced online transition may add some stressful elements to the already difficult situation, generating additional personal concerns of not being able to follow the course online and to finish it due to the augmented workload and shifts.

Langegår et al. (2021) highlighted that students experienced deterioration in some pedagogical aspects after the transition from campus learning to online learning. Ibrahim et al. (2021) highlighted that after an adaptation period followed a rapid transition to a new normality. In our study, participants considered the relational and affective dimensions as a fundamental positive intrinsic value of their personal concept of educational life, whereas they initially depicted a new didactic setting where such dimensions were drastically reduced (Pierce et al., 2020; Sandars et al., 2020).

Furthermore, in the beginning, some students perceived their face-to-face learning experience as having a broader perspective than online learning (Regmi 
\& Jones, 2020). They highlighted some examples of lived situations influencing positively their pre-lockdown experience of educational life, like the preparation for the trip to the university, the trip itself, or meeting other students during coffee breaks. These first perceptions, however, changed by recognizing technology also as a resource and as an element for a new form of socialization (Pierce et al., 2020).

They expressed initial concerns about missing the chance to observe and to be physically in the class, to interact, ask questions, or follow other students' reasoning, which for some of them is also an element of facilitation of learning and quality of educational life (Fawns et al., 2019). The missing interaction interpreted as missing the embodiment of the educational experience was a topic highlighted in the interviews by students attending courses with less theoretical programs, like intensive care specializing courses (Bączek et al., 2021).

During our research, study participants showed also an optimistic and general appreciation of the advantages that the online learning transition brought to the quality of their educational life in terms of time, access, less traveling, reduced cost of accommodation and transportation in other settings; moreover, it appeared that online learning materials were also delivered faster (Bączek et al., 2021). A new aspect, enabling the educational life, explored by students was the discovery of the advantages of new media of communication gained from the online setting, like the faster response and contact with teachers and tutors, fewer time boundaries and generally the sense of continuous and available connection with fellow students (Zhou et al., 2020). In fact, some participants perceived the digital transformation as a chance to create new relationships and a useful introduction to new platforms for socialization (Pierce et al., 2020). Some students highlighted that the fundamental relational dimension of the learning experience could be enriched by the new possibilities, suggesting that meaningful interactions can, and do occur online and they may help to develop resilience (Fawn et al., 2019). Our study participants, although possessing several levels of digital literacy highlighted a surprising adaptation to the new setting, showing little difference with digital natives' perceptions (Mladenova et al., 2020). In addition to this, online tutors, who can help students navigating throughout the journey into the new setting, can facilitate the new socialization process (Jowsey et al., 2020). Students highlighted also the figure of the online tutor as an important element of engagement improvement and support to facilitate the personalization of learning and the quality of teaching life.

Although some ambiguities emerged among students who initially expressed a strong desire to "go back to normal teaching", most students discovered that the new teaching method could be adapted to their lifestyle. This is an important aspect especially in a specific historical demanding moment for health professionals, which leads them to the risk of experiencing negative consequences on their physical and mental health. Therefore, it was acknowledged that the new teaching method favors the acquisition of a better educational life and an enhanced overall quality of life. Study participants foresee an evolution of their 
educational life and university pathway towards a blended learning modality. This aspect highlights the effort of academics to create an e-learning environment more adapted to students' life than to organizations' demands. Finally, our study results showed themes aligned with current research concerning what the participants perceived, at least initially, of the change in teaching induced by the Covid. However, they also identified elements of novelty, specifically linked not just to the learning experience but also to a more comprehensive dimension of the quality of educational life. Thus, they acknowledged that interpersonal relationships can also exist in online learning and that both the personal attitude of the students and that of the teacher/tutor can greatly influence the quality of teaching life. Participants even recognize that one can also be "coached" to online education and learning. Furthermore, our results highlighted elements of educational life suggesting a new curricular design to support academics (Cleland et al., 2020).

\section{Implications for Practice}

Improvement of students' quality of educational life can be achieved by implementing professionals and academics' engagement in acquiring new digital skills and developing new competency in e-learning. Adult learners might be encouraged to observe and engage in online learning opportunities as part of their lifelong professional development by teachers and academics aware of the meaning of quality of educational life. Lastly, stakeholders and academia implementing online learning programs need to consider and value the high impact of online tutoring and coaching on students' learning outcomes and quality of educational life.

\section{Conclusion}

The present study highlighted that the quality of educational life was maintained at a high level albeit the sudden shift from face-to-face to e-learning training methods and participants' endangered quality of life, due to professional and personal consequences of Covid emergency. Participants recognized new elements supporting their quality of educational life like the discoveries of the advantages of the use of technology, and that relationships are not lost but morph into new ones by activating resilience and proactivity. This study suggests to academics to consider further elements that enable and improve the quality in the educational life of students, and to value the complexity of its meanings.

\section{Strengths and Limitations}

Our research project was unique, being focused on the perceptions of quality of educational life during the forced transition to online learning by working healthcare professionals who attended postgraduate courses. However, study limitations can be given by the fact that the total population of the study was composed of only 24 respondents: this number, while deepening the study phe- 
nomenon in detail, at a local level, could make it difficult to transfer these results over a large scale. Therefore, it is suggested to implement future research aiming at exploring the phenomenon of quality of educational life.

\section{Authorship Statement}

LS and GA contributed to the study conception and design. VDN, LD and FM performed material preparation and data collection. Data analysis was conducted by LS, GA, EDL, CM and VCC. The manuscript was written by LS, GA, EDL and CM. All authors commented on previous versions of the manuscript. All authors read and approved the final manuscript.

\section{Conflicts of Interest}

The authors declare no conflicts of interest regarding the publication of this paper.

\section{References}

Aitken, G. (2020). A Post Digital Exploration of Online Postgraduate Learning in Healthcare Professionals: A Horizontal Conception. Postdigital Science and Education, 3, 181-197. https://doi.org/10.1007/s42438-020-00103-w

An, Y., Yang, Y., Wang, A., Li, Y., Zhang, Q., Cheung, T. et al. (2020). Prevalence of Depression and Its Impact on Quality of Life among Frontline Nurses in Emergency Departments during the COVID-19 Outbreak. Journal of Affective Disorders, 276, 312-315. https://doi.org/10.1016/j.jad.2020.06.047

Bączek, M., Zagańczyk-Bączek, M., Szpringer, M., Jaroszyński, A., \& WożakowskaKapłon, B. (2021). Students' Perception of Online Learning during the COVID-19 Pandemic: A Survey Study of Polish Medical Students. Medicine, 100, e24821. https://doi.org/10.1097/MD.0000000000024821

Basilaia, G., \& Kvavadze, D. (2020). Transition to Online Education in Schools during a SARS-CoV-2 Coronavirus (COVID-19) Pandemic in Georgia. Pedagogical Research, 5, em0060. https://doi.org/10.29333/pr/7937

Braun, V., \& Clarke, V. (2006). Using Thematic Analysis in Psychology. Qualitative Research in Psychology, 3, 77-101. https://doi.org/10.1191/1478088706qp063oa

Braun, V., \& Clarke, V. (2014). What Can "Thematic Analysis" Offer Health and Wellbeing Researchers? International Journal of Qualitative Studies on Health and Well-Being, 9, Article ID: 26152. https://doi.org/10.3402/qhw.v9.26152

Busch, I. M., Moretti, F., Mazzi, M., Wu, A. W., \& Rimondini, M. (2021). What We Have Learned from Two Decades of Epidemics and Pandemics: A Systematic Review and Meta-Analysis of the Psychological Burden of Frontline Healthcare Workers. Psychotherapy and Psychosomatics, 90, 178-190. https://doi.org/10.1159/000513733

Cappi, V, Artioli, G., Erika, N., Silvia, F., Maria, C. G., Gianfranco, M., \& Sarli, L. (2019). The Use of Blended Learning to Improve Health Professionals' Communication Skills: A Literature Review. Acta Bio Medica: Atenei Parmensis, 90, 17-24.

Cleland, J., Tan, E. C. P., Tham, K. Y., \& Low-Beer, N. (2020). How Covid-19 Opened up Questions of Sociomateriality in Healthcare Education. Advances in Health Sciences Education, 25, 479-482. https://doi.org/10.1007/s10459-020-09968-9

Dewart, G., Corcoran, L., Thirsk, L., \& Petrovic, K. (2020). Nursing Education in a Pan- 
demic: Academic Challenges in Response to COVID-19. Nurse Education Today, 92, Article ID: 104471. https://doi.org/10.1016/j.nedt.2020.104471

Elitok Kesici, A., \& Çavus, B. (2019). University Life Quality and Impact Areas. Universal Journal of Educational Research, 7, 1376-1386.

https://doi.org/10.13189/ujer.2019.070605

Erez, A. B. H., Kuhle, S., McIsaac, J. L., \& Weintraub, N. (2020). School Quality of Life: Cross-National Comparison of Students' Perspectives. Work, 67, 573-581. https://doi.org/10.3233/WOR-203310

Fawns, T., Aitken, G., \& Jones, D. (2019). Online Learning as Embodied, Socially Meaningful Experience. Postdigital Science and Education, 1, 293-297.

https://doi.org/10.1007/s42438-019-00048-9

Goni-Fuste, B., Wennberg, L., Martin-Delgado, L., Alfonso-Arias, C., Martin-Ferreres, M. L., \& Monforte-Royo, C. (2021). Experiences and Needs of Nursing Students during Pandemic Outbreaks: A Systematic Overview of the Literature. Journal of Professional Nursing, 37, 53-64. https://doi.org/10.1016/j.profnurs.2020.12.004

Graneheim, U. H., Lindgren, B. M., \& Lundman, B. (2017). Methodological Challenges in Qualitative Content Analysis: A Discussion Paper. Nurse Education Today, 56, 29-34. https://doi.org/10.1016/j.nedt.2017.06.002

Ibrahim, N. K., Al Raddadi, R., AlDarmasi, M., Al Ghamdi, A., Gaddoury, M., AlBar, H. M., \& Ramadan, I. K. (2021). Medical Students' Acceptance and Perceptions of e-Learning during the Covid-19 Closure Time in King Abdulaziz University, Jeddah. Journal of Infection and Public Health, 14, 17-23.

https://doi.org/10.1016/j.jiph.2020.11.007

Jowsey, T., Foster, G., Cooper-Ioelu, P., \& Jacobs, S. (2020). Blended Learning via Distance in Pre-Registration Nursing Education: A Scoping Review. Nurse Education in Practice, 44, Article ID: 102775. https://doi.org/10.1016/j.nepr.2020.102775

Karimi, M., \& Brazier, J. (2016). Health, Health-Related Quality of Life, and Quality of Life: What Is the Difference? Pharmaco Economics, 34, 645-649. https://doi.org/10.1007/s40273-016-0389-9

Korkmaz, S., Kazgan, A., Çekiç, S., Tartar, A. S., Balc1, H. N., \& Atmaca, M. (2020). The Anxiety Levels, Quality of Sleep and Life and Problem-Solving Skills in Healthcare Workers Employed in COVID-19 Services. Journal of Clinical Neuroscience, 80, 131-136. https://doi.org/10.1016/j.jocn.2020.07.073

Langegård, U., Kiani, K., Nielsen, S. J., \& Svensson, P. A. (2021). Nursing Students’ Experiences of a Pedagogical Transition from Campus Learning to Distance Learning Using Digital Tools. BMC Nursing, 20, Article No. 23.

https://doi.org/10.1186/s12912-021-00542-1

Martin, F., \& Bolliger, D. U. (2018). Engagement Matters: Student Perceptions on the Importance of Engagement Strategies in the Online Learning Environment. Online Learning, 22, 205-222. https://doi.org/10.24059/olj.v22i1.1092

Martinengo, L., Yeo, N. J. Y., Kasturi, D., Markandran, O., Olsson, M., Kyaw, B. M., \& Car, L. T. (2020). Digital Health Professions Education on Chronic Wound Management: A Systematic Review. International Journal of Nursing Studies, 104, Article ID: 103512. https://doi.org/10.1016/j.ijnurstu.2019.103512

Mladenova, T., Kalmukov, Y., \& Valova, I. (2020). Covid 19-A Major Cause of Digital Transformation in Education or Just an Evaluation Test. TEM Journal, 9, 1163-1170. https://doi.org/10.18421/TEM93-42

Nowell, L. S., Norris, J. M., White, D. E., \& Moules, N. J. (2017). Thematic Analysis: Striving to Meet the Trustworthiness Criteria. International Journal of Qualitative Me- 
thods, 16, Article ID: 1609406917733847. https://doi.org/10.1177/1609406917733847

Patton, M. Q. (1999). Enhancing the Quality and Credibility of Qualitative Analysis. Health Services Research, 34, 1189-1208.

Pedro, E., Leitão, J., \& Alves, H. (2016). Does the Quality of Academic Life Matter for Students' Performance, Loyalty and University Recommendation? Applied Research in Quality of Life, 11, 293-316. https://doi.org/10.1007/s11482-014-9367-6

Pei, L., \& Wu, H. (2019). Does Online Learning Work Better than Offline Learning in Undergraduate Medical Education? A Systematic Review and Meta-Analysis. Medical Education Online, 24, Article ID: 1666538. https://doi.org/10.1080/10872981.2019.1666538

Pierce, L. M., Weber, M. J., Klein, C. J., \& Stoecker, B. A. (2020). Transitioning an Advanced Practice Fellowship Curriculum to eLearning during the COVID-19 Pandemic. Journal of Nursing Education, 59, 514-517. https://doi.org/10.3928/01484834-20200817-07

Ramos-Morcillo, A. J., Leal-Costa, C., Moral-García, J. E., \& Ruzafa-Martínez, M. (2020). Experiences of Nursing Students during the Abrupt Change from Face-to-Face to e-Learning Education during the First Month of Confinement Due to COVID-19 in Spain. International Journal of Environmental Research and Public Health, 17, Article No. 5519. https://doi.org/10.3390/ijerph17155519

Regmi, K., \& Jones, L. (2020). A Systematic Review of the Factors-Enablers and Barriers-Affecting e-Learning in Health Sciences Education. BMC Medical Education, 20, Article No. 91. https://doi.org/10.1186/s12909-020-02007-6

Sandars, J., Correia, R., Dankbaar, M., de Jong, P., Goh, P. S., Hege, I. et al. (2020). Twelve Tips for Rapidly Migrating to Online Learning during the COVID-19 Pandemic. MedEdPublish, 9, Article No. 82. https://doi.org/10.15694/mep.2020.000082.1

Simpson, W., Patel, K. D., \& Reeves, S. (2020). Investigating Online Interprofessional Learning and Communication Using Social Network Analysis: A Study Protocol. Journal of Interprofessional Care, 34, 566-568. https://doi.org/10.1080/13561820.2019.1674258

Sirgy, M. J., Grzeskowiak, S., \& Rahtz, D. (2007). Quality of College Life (QCL) of Students: Developing and Validating a Measure of Well-Being. Social Indicators Research, 80, 343-360. https://doi.org/10.1007/s11205-005-5921-9

Sirgy, M. J., Lee, D. J., Grzeskowiak, S., Grace, B. Y., Webb, D., El-Hasan, K. et al. (2010). Quality of College Life (QCL) of Students: Further Validation of a Measure of Well-Being. Social Indicators Research, 99, 375-390. https://doi.org/10.1007/s11205-010-9587-6

Tong, A., Sainsbury, P., \& Craig, J. (2007). Consolidated Criteria for Reporting Qualitative Research (COREQ): A 32-Item Checklist for Interviews and Focus Groups. International Journal for Quality in Health Care, 19, 349-357. https://doi.org/10.1093/intqhc/mzm042

Waddington, A., \& Porter, S. (2021). Developing Social Presence in Online Learning among Nurses: Exploration of the Community of Inquiry Models Domain of Social Using a Qualitative Descriptive Design. Nurse Education in Practice, 52, Article ID: 103000. https://doi.org/10.1016/j.nepr.2021.103000

Zhou, T., Huang, S., Cheng, J., \& Xiao, Y. (2020). The Distance Teaching Practice of Combined Mode of Massive Open Online Course Micro-Video for Interns in Emergency Department during the COVID-19 Epidemic Period. Telemedicine and e-Health, 26, 584-588. https://doi.org/10.1089/tmj.2020.0079 